\title{
Research on Shanxi Museum Development Countermeasures Based on Tourists' Perception
}

\author{
Zeqin Liu* \\ School of Economics and Management, Beijing Jiaotong University, China \\ *Corresponding author.Email: 20120726@bjtu.edu.cn
}

\begin{abstract}
Museums, as an important part of cultural tourism, have become an important hub of cultural tourism integration, and researching on the subject of museum tourism has become a hot spot. Based on this, this article conducts a preliminary discussion and research on the perception of tourists in Shanxi Museum. First, This paper builds a system of influencing factors of tourists' perception in Shanxi Museum, and lists 35 factors that influence tourists' perception from three aspects: tourism resources, tourism services and tourism environment. Second, using the IPA analysis method combined with the paired t-test, by analyzing the degree of difference in satisfaction and importance, the factors of the three dimensions are analyzed separately. Finally, it was found that tourists' satisfaction with Shanxi Museum's exhibitions, cultural and creative development, and transportation environment were significantly lower. This paper puts forward the tourism development countermeasures of Shanxi Museum in terms of display, activities, cultural creation and tourism environment based on the research.
\end{abstract}

Keywords: Museum tourism, Tourist perception, IPA analysis method, Shanxi Museum.

\section{INTRODUCTION}

According to data from the National Bureau of Statistics of China, as of the end of 2018, the total number of museums in China reached 4,918, and the number of museum visitors reached 104,403,800. Museum tourism has become an important form of integrated development of culture and tourism. In the process of increasing the cultural needs of the people, the focus of attention of tourists has changed from "have or don't have" to "good or not good". In such a transformation, tourists' perception of museums affects their evaluation of the quality of tourism products, market development and sustainable development of tourist destinations.

\section{LITERATURE REVIEW}

Foreign research on tourists' perception of museums mainly uses quantitative analysis to make it clear that the quality of the museum is determined by the designers, managers and tourists, so as to promote the marketing of the museum. The domestic research on museum visitor behavior is mainly the research on tourists' psychology and travel motivation, using economics and statistics related methods. Nowacki (2005) created a tourist perception system and used the "SERVQUAL" evaluation method to allow participants to evaluate 36 indicators of museum exhibitions and tour commentary [1]. Zhu Ye (2006) used the ASEB grid method to study the experience of tourists. By studying the experience perception of tourists, he pointed out that the products provided by the museum are quite different from the needs of tourists [2]. He Dan (2017) analyzed the text of online reviews of Beijing regional museums, and used the text content analysis method to study the tourist perception experience of tourist museum tourism [3]. Zuo Shuai (2019) found out the defects of Nanjing Museum and the corresponding improvement methods from the three aspects of brand, service and potential through the investigation and analysis of the satisfaction of visitors to Nanjing Museum [4]. Based on the research on tourist perception and the current development of Shanxi Museum, this paper establishes an index system that affects the perception of tourists in Shanxi Museum, and uses IPA analysis to analyze the importance and satisfaction of various factors, so as to propose countermeasures for the tourism development of Shanxi Museum.

\section{INFLUENCE FACTOR ANALYSIS PROCESS}

\subsection{Indicator System and Data Source}

The SERVQUAL scale proposed by Parasuraman, Zeithaml and Berry focuses on measuring general service quality, including five dimensions: reliability, responsiveness, assurance, empathy and tangibility[5];The comprehensive museum tourism experience quality evaluation system constructed by 
Table 1. Influencing factors system of tourist perception

\begin{tabular}{|c|c|c|}
\hline Primary Factor & Secondary Factor & Tertiary Factor \\
\hline \multirow{12}{*}{ Travel Resources } & \multirow{6}{*}{ Display content } & The richness of the collection \\
\hline & & The preciousness of the collection \\
\hline & & The educational value of the collection \\
\hline & & $\begin{array}{l}\text { The historical value of the collection } \\
\text { Collection visibility }\end{array}$ \\
\hline & & Collections show local cultural level \\
\hline & & Prominence of exhibition theme \\
\hline & \multirow{3}{*}{ Display form } & Display atmosphere \\
\hline & & Display lighting design \\
\hline & & Digital display \\
\hline & \multirow{3}{*}{ Othernon-material resources } & Research activities \\
\hline & & Theme exhibition activities \\
\hline & & Cultural experience activities \\
\hline \multirow{16}{*}{ Travel services } & \multirow{11}{*}{ Supporting services and prices } & Catering services \\
\hline & & Food prices \\
\hline & & Explain services \\
\hline & & Explain prices \\
\hline & & Cultural and Creative Product Features \\
\hline & & Cultural and creative product categories \\
\hline & & Cultural and creative product prices \\
\hline & & Employee image \\
\hline & & Staff service attitude \\
\hline & & Parking lot \\
\hline & & Parking fee rates \\
\hline & \multirow{4}{*}{ Hardware service } & Digital service equipment \\
\hline & & Public health facilities in the hall \\
\hline & & Identification system \\
\hline & & Elevator equipment \\
\hline & Other service & Museum opening hours \\
\hline \multirow{6}{*}{ Tourism environment } & \multirow{3}{*}{ Surroundings } & Building exterior design \\
\hline & & Traffic convenience \\
\hline & & Greening level \\
\hline & \multirow{3}{*}{ Internal environment } & Pavilion interior design \\
\hline & & Exhibition hall hygiene \\
\hline & & Public security situation \\
\hline
\end{tabular}

Zhang Yuan includes three dimensions: communication, tangibility, reliability, responsiveness, empathy and assurance [6]; the evaluation system designed by Zhang Chunxiang when studying the perception of tourists in the Tunken Cultural Museum includes core tourist attractions, Four types of factors, facilities, services and environment[7]. Based on the above literature research and the development status of Shanxi Museum, this paper establishes an indicator system from the dimensions of museum tourism resources, services and environment, and connects tourists to fill out questionnaires through online social platforms. The questionnaire mainly includes the importance and perception of these factors for toutists and the personal information of the tourists. 205 questionnaires and 202 valid questionnaires were collected in this survey, with an efficiency of $98.5 \%$.

\subsection{Reliability and Validity Analysis}

This paper uses the Crobach $\alpha$ coefficient to evaluate the reliability. In this study, the Crobach $\alpha$ values of various factors such as tourism resources, tourism services and tourism environment are all greater than 0.8 , indicating that the reliability of the questionnaire survey is reliable. Validity refers to the degree to which a concept can be measured by the scale of this concept. This study uses KMO and Bartley spheres for validity analysis. In this study, the KMO values of tourism resources, tourism services and tourism environment are all greater than 0.8 , and the significance of Bartlett's sphericity test is less than 0.05 , which is suitable for factor analysis.

\subsection{Descriptive Analysis}

This part is to analyze the gender, age, habitual residence, occupation, travel purpose, educational background, etc. of the surveyed person. The purpose is to understand the composition of tourists in Shanxi Museum. In terms of gender, there are more female tourists than male tourists; in terms of age, the number of respondents aged 18 to 25 is the largest, accounting for $61.9 \%$; in terms of permanent residence, the number 
of tourists in this city is higher than that of foreign tourists; in terms of occupation, tourists are middle school students There are a large number of teachers and teachers. In addition, there are more technical R\&D personnel and management personnel, accounting for $5.9 \%$ and $5.0 \%$ respectively. In terms of travel purpose, this question is a multiple-choice question. As can be seen from the table, the most tourists are for growth Knowledge, followed by improving self-cultivation, and satisfying curiosity, accounted for $84.2 \%, 67.3 \%$ and $61.9 \%$ respectively. There are $44 \%$ of tourists traveling to participate in activities. In terms of academic qualifications, the tourists from Shanxi Museum who filled out the questionnaire had higher academic qualifications. The number of undergraduate and above and junior college students were 166 and 23, respectively, accounting for $83 \%$ and $11 \%$ respectively.

\subsection{IPA Analysis}

This study uses the IPA analysis chart combined with the results of the paired test to analyze. The purpose of the paired t-test is to test whether there is a significant difference between the two values (Importance and Performance) of each team of 35 pairs of tourist perception factors in Shanxi Museum, combined with IPA positioning the map better clarifies the importance and degree of satisfaction of each factor.

\subsubsection{IPA Analysis of Tourism Resources}

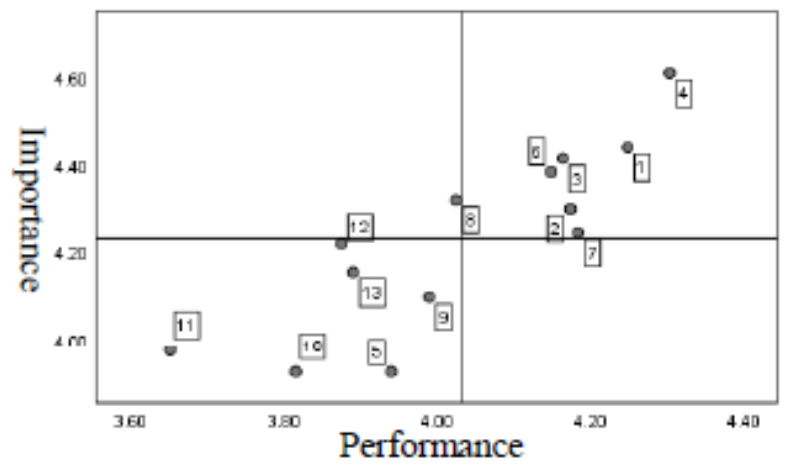

Figure 1 IPA positioning map of tourism resources

According to the IPA positioning map, the only factor in the second quadrant is the display atmosphere (8), which shows that the display atmosphere of Shanxi Museum's collections is very important in the minds of tourists, but the performance in this respect does not satisfy the tourists. Atmosphere ( $\mathrm{t}$-value $=2.900$, two-tailed $\mathrm{p}$-value $=0.004<0.050$ ), which shows that there is a significant difference between importance and performance, and is an item that needs to be improved. The paired test results of factor research activities and theme exhibition activities in the third quadrant were $(\mathrm{t}$ value $=3.001$, two-tailed $\quad \mathrm{p}$-value $=0.003<0.050$ ) ( $\mathrm{t}$-value $=3.484, \quad$ two-tailed $\quad \mathrm{p}$-value $=0.001<0.050$ ), indicating There are significant differences in performance and importance, and tourist satisfaction is low.

\subsubsection{IPA Analysis of Tourism Services}

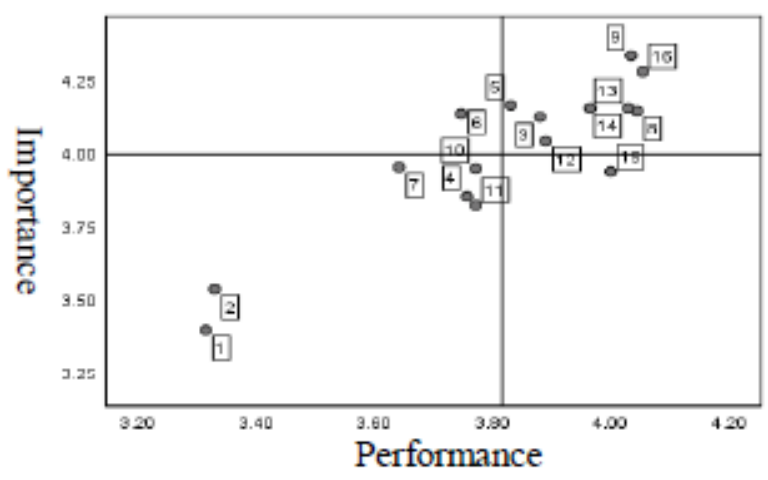

Figure 2 Location map of tourism service IPA

According to the principle of IPA analysis, the only factor in the second quadrant is the category of cultural and creative products (6), indicating that the cultural and creative types of Shanxi Museum are very important in the minds of tourists, but the performance in this aspect does not satisfy the tourists, and The types of cultural and creative products ( $\mathrm{t}$-value $=4.146$, two-tailed $\mathrm{p}$-value $=0.000<0.050$ ) have significant differences in importance and performance, and are items that need to be improved. The factor in the third quadrant is the factor with the difference in importance and performance. The paired test result of cultural and creative product prices is $(\mathrm{t}$ value $=2.597$, two-tailed $\mathrm{p}$ value $=0.010<0.050$ ), which shows that there are significant differences in performance and importance, and tourist satisfaction is very low.

\subsubsection{IPA Analysis of Tourism Environment}

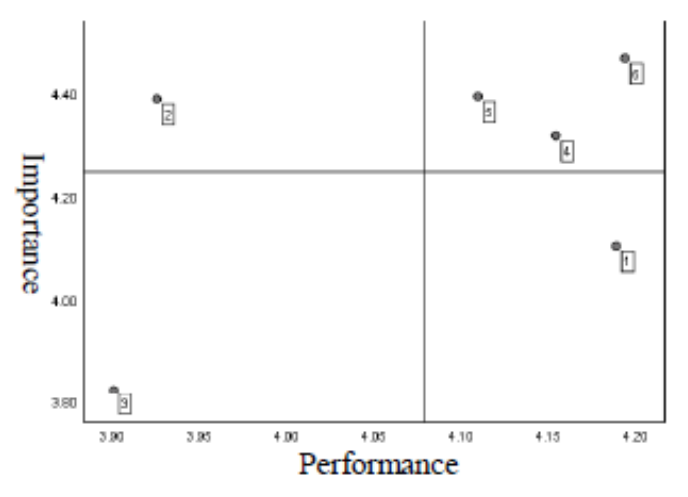

Figure 3 Location Map of Tourism Environment IPA

The only factor located in the second quadrant is traffic convenience (2). According to the principle of IPA analysis, the factor located in this quadrant is the most important factor in the four quadrants, indicating that it is very important in the eyes of tourists, but in 
this respect The performance does not make tourists very satisfied. The only factor in the third quadrant is the greening level (3). According to the principle of IPA analysis, the factors located in this quadrant are the factors that are poor in importance and performance. The current level of greening needs to be improved slowly.

\section{Results Analysis}

\subsection{Reasonable Use of Resources}

In terms of tourism resources, the main areas that Shanxi Museum needs to improve are: display atmosphere, research activities, and theme exhibition activities. In terms of tourism resources, Shanxi Museum has the problem of insufficient display of the educational value and cultural connotation of its collections. Therefore, the Shanxi Museum should dig deeper into the connotation of its products: first, establish a sound museum scientific research system, and strengthen cooperation with universities and other cultural and cultural institutions; second, give play to the role of cultural and creative center, and develop products to display the connotation of cultural relics, set up and collect Display matching cultural and creative brand images, improve the content of product labels, and include cultural relics manuals and creative concepts; third, innovate the content and form of activities, organize bronze production activities, museum treasure digging activities, and cooperate with cultural and creative stores to launch assembly competitions, etc. More creative, technological and cultural activities.

\subsection{Optimize Travel Services}

In terms of tourism services, Shanxi Museum's main areas to be improved are: the types and prices of cultural and creative products, the opening hours of the museum, and the tourism identification system.If Shanxi Museum wants to improve the level of tourism services, it is recommended to start with the following aspects: First, establish a sense of responsibility for maintaining the image of the museum. Through regular team building activities and museum history training activities, employees can accept the culture spread by the museum from their hearts. The second is to provide regular professional training for employees, and regular sales training for cultural and creative store employees. The third is to enhance staff service awareness, set up museum service days, share heart-warming stories between staff and visitors, and remind staff to pay attention to tourist services.

\subsection{Improve the Tourist Environment}

In terms of tourism environment, Shanxi Museum needs to be improved mainly in the following aspects: traffic convenience and greening level.The data analysis results show that tourists are less satisfied with the convenience of transportation. The museum should solve the problem through departmental cooperation: First, cooperate to establish urban tourism transportation lines to connect scenic spots; second, cooperate with the transportation department on the museum day Add a navigation logo. In addition, as a part of public cultural life, museums should organize community activities to cultivate small and elderly volunteer teams to integrate into the community. Furthermore, whether it is the creation of the museum's display atmosphere or the maintenance of the exhibition hall's sanitation, tourists' actions are inseparable, and the awareness of civilized tours can be enhanced through the Civilized Tourism Day activities.

\section{CONCLUSION}

With the in-depth development of cultural and tourism integration and the application of tourist perception research in the field of museums, this paper uses network questionnaire surveys and IPA analysis to analyze the perception of tourists in Shanxi Museum, and proposes countermeasures for tourism development in Shanxi Museum. Through the IPA analysis of 35 factors such as tourism resources, services and environment, the problems in the tourism development of Shanxi Museum were found and suggestions were made.

In the end, it was found that in terms of source of tourists, the number of foreign tourists is small and the number of local tourists is relatively large; in the tourism environment, there are problems of low form satisfaction, insufficient educational value of collections to reflect and display local culture, and low satisfaction in research activities; in tourism services, there are problems There are few types and prices of cultural and creative creations, the development time of the museum and the low satisfaction of the marking system; the transportation convenience and the sanitary environment of the exhibition hall need to be improved in the tourism environment. Finally, in response to the problems found, this paper believes that Shanxi Museum should dig deep into the cultural connotation of tourism resources, ensure the quality of display and innovate theme activities; in tourism services, it should pay attention to the development of cultural creativity, strengthen talent management and strengthen the level of intelligence; The tourism environment should cooperate with transportation departments and surrounding communities, and at the same time encourage tourists to travel in a civilized manner; in addition, the museum should strengthen tourism promotion and actively cooperate with universities and cultural tourism enterprises. 
In the research process, due to the limited ability of oneself, there are deficiencies in data collection and data analysis. In the subsequent museum tourism research, we should explore the balance between tourist needs and collection protection, and explore more suitable paths for museum tourism resources development.

\section{REFERENCES}

[1] Marek M Nowacki. Evaluating a museum as a tourist product: using the servqual method [J]. Museum Management and Curatorship, 2005, 20(3):235-250.

[2] Zhu Ye. Discussion on Tourism Development Strategy of Folk Museum Based on Tourists [J]. Shopping Mall Modernization, 2006(30):156-158.

[3] He Dan, Li Xueyan, Zhou Aihua, Fu Xiao. Research on Museum Tourism Experience in Beijing Area_Based on Internet Text Analysis of Dianping.com [J]. Resource Development and Market, 2017, 33(02): 233-237.
[4] Zuo Shuai, Jia Hongyan. Research on the Improvement of Museum's Tourism Experience from the Perspective of Tourist Satisfaction-Taking Nanjing Museum as an Example [J]. Comparative Research on Cultural Innovation, 2019, 3(22):162-164.

[5] Parasuraman.A.,Zeithaml.V.A.,Berry.L.L.SERVQU AL:A multiple-item scale for measuring consumer perceptions of service quality[J].Journal of Retailing 1988,64(1):12-40

[6] Zhang Yuan. The construction and empirical research of comprehensive museum tourism experience quality evaluation system [D]. Soochow University, 2015.

[7] Zhang Chunxiang. Research on the Tourist Perception Evaluation System of Tunken Museum Based on Factor Analysis: Taking Xinjiang Corps Army Reclamation Museum as an example [J]. Resource Development and Market, 2018, 34(03): 433-438. 